\title{
Towards a 'heterotopology' of gaming: From Azeroth to Sanctuary
}

\author{
DOI: http://doi.org/10.26758/9.1.11
}

Mihai BURLACU

Department of Social Sciences and Communication, Transilvania University, Romania

Address correspondence to: Mihai Burlacu, Department of Social Sciences and Communication, Transilvania University, 29, Eroilor Boulevard, Room TII9, Brașov, BV 500036, Romania, Ph.: 0040-740-884-963; E-mail: mihai.burlacu@unitbv.ro

\begin{abstract}
Objectives. In this article, Michel Foucault's (1967) theoretical insights regarding heterotopias are reconsidered, in order to determine whether his 'heterotopology' can be mirrored in several virtual worlds that are constantly redefined and reimagined by game producers and gamers alike. The places represented and juxtaposed in MMORPG's like World of Warcraft epitomize countless virtual worlds full of contradictions, paradoxes and representations of the 'Other'.

Material and methods: Towards a 'heterotopology' of virtual worlds. Drawing upon ingame participant observation, the main argument is that the plethora of emplacements and cultural references from virtual worlds like Azeroth and Sanctuary underline their paradoxical character. These worlds appear to simultaneously connect and differentiate between various spaces and times. Furthermore, they connect and contextualize multiple meanings, which can be interpreted from an anthropological standpoint.

Results. The juxtapositions between the various meanings entailed by these worlds are relevant only through the ways in which they encompass and exemplify the contradictions that exist in reality, without including solutions for them.

Conclusions. Accordingly, the ways in which virtual worlds such as Azeroth are reimagined highlight the need of redefining the conceptual relevance of heterotopia.
\end{abstract}

Keywords: heterotopia, heterotopology, virtual world.

\section{Introduction}

The applications of Michel Foucault's 'heterotopology' have been debated in various fields of research in the past half-century, bridging Cultural Anthropology to Architecture, and Sociology to Urban Planning. Accordingly, Foucault's theoretical insights regarding heterotopias have constituted the basis for a corpus of knowledge dedicated to 'other spaces'. In this article, his insights are reconsidered, in order to ascertain if the 'heterotopology' can be mirrored in several virtual worlds that are regularly redefined and reimagined by game producers, developers and gamers.

The multiple juxtapositions entailed by virtual worlds like Azeroth and Sanctuary connect multiple spaces, times and meanings. They interfere with the continuity of the 'ordinary space'. This article represents a development of a previous excursus, in which it was asserted that a virtual world is essentially a multileveled heterotopia where the digital counterparts of real objects seem more 'real' and 'compelling' than the originals (Palfrey and Gasser, 2008; Burlacu, 2017). The article begins with a review of the inception of 'heterotopia' in the social sciences. It continues with a brief exposition of Foucault's 'heterotopology'. Afterwards, the article contains 
several considerations pertaining to the applications of Foucault's principles in describing virtual worlds like Azeroth or Sanctuary.

This excursus requires some preliminary clarifications vis-à-vis Foucault's attempt to envisage the new and original type of spatial analytics called 'heterotopology' (i.e. fr. 'hétérotopologie'). The fundamental concept that is approached in this article, heterotopia, is actually borrowed from the medical discourse, where it designates a tissue with an anomalous location or a displaced organ (Boyer, 2008, p. 58). As places of Otherness, heterotopias are "sites constituted in relation to other sites by their difference", according to Kevin Hetherington (1997, p. viii). The concept is extensionally vast and its description is somewhat ambiguous. Despite its vagueness, in the five decades, Foucault's principles regarding heterotopias have garnered a significant notoriety among architects and social scientists.

\section{Inception of Heterotopia}

The first lecture dedicated to this concept was presented on the $14^{\text {th }}$ of March 1967 at the Cercle d'études architecturales, which at that time was directed by Ionel Schein and Jean Dubuisson. Foucault held this lecture after Schein heard his thesis in a radio talk entitled "Les Hétérotopies" that was broadcasted on France Culture, in December 1966. Actually, Foucault had written his lecture during his stay in Sidi-Bou-Saïd, Tunisia (Faubion, 2008, pp. 31-39). In the same period he was writing L'archéologie du savoir ("The Archaeology of Knowledge") and trying to elucidate the issues generated by the concepts used in his 1966 book, entitled Les Mots et les choses: Une archéologie des sciences humaines ("The Order of Things: An Archaeology of the Human Sciences"). He left France for Sidi-Bou-Saïd in September 1966 in order to avoid the commotion generated by the publication of this book. Furthermore, his lecture was derived from an idea regarding utopias and heterotopias from the same book.

In a nutshell, Foucault linked in Les Mots et les choses the two concepts with language. On the one hand, he claimed that utopias illustrate stories about imaginary non-places. On the other hand, heterotopias "secretly undermine language, because they make it impossible to name this and that, because they shatter or tangle common names, because they destroy 'syntax' in advance [sic!]" (Foucault, 2002, p. XIX). While utopias allow the development of language, heterotopias destroy the existential fundaments for any grammar. Interestingly, Christine Boyer points out that in his radio broadcast, Foucault uses the concept of 'heterotopia' in order to present his insights regarding space, not language (Boyer, 2008, p. 55).

It is considered relevant to stress the fact that even though in "Des Espace Autres" ("Of Other Spaces") Foucault continues to highlight heterotopias as 'other spaces', they are presented as spaces that entail juxtaposed meanings. Unlike Boyer's paper, this article is not based on the idea that Foucault connected utopias and heterotopias exclusively with language in Les Mots et les choses. Actually, in his later lectures he doesn't describe his concept exclusively in spatial terms. By emphasizing the fact that heterotopias are spaces entailing juxtaposed meanings, Foucault hints that his 'heterotopology' should not be confined within the limits of proxemics, architecture or topology, and it shouldn't be understood in terms of language. Therefore, his third principle, stating that "the heterotopia has the power to juxtapose in a single real place several spaces, several emplacements that are in themselves incompatible" hints to a semiotic perspective (Foucault, 2002, p. 19). His examples have one thing in common: heterotopias are places in which multiple spaces can be juxtaposed in terms of meaning. It could be argued that heterotopias are ultimately places that juxtapose multiple meanings and not spaces per se.

The progressive incorporation of digital technology into people's everyday life opened new horizons and created new places that simultaneously connect and invert various spaces and times. This excursus is built upon previous articles in which there were addressed the emergence and proliferation of these new places that can be called 'virtual heterotopias' (Burlacu, 2014; 
2015; 2017). The main aspect that makes 'virtual heterotopias' an attractive topic of research resides in the amalgamation or juxtaposition of traits from several types of heterotopias described by Foucault. Analogous to mirrors, they offer people the possibility of having avatars, which are actually similar to Foucault's 'shadow' (2008, p. 17). Thus, each individual gets her/his own visibility, and as such, people can see themselves where they are not. 'Virtual heterotopias' are paradoxical, because they are both illusory and meticulously arranged. Indeed, many virtual worlds are immersive because they were designed as places of compensation.

\section{Juxtapositions reconsidered: Foucault's 'heterotopology'}

Heterotopias are places characterized by the relativity of the times and spaces they simultaneously represent, contest, invert, contain and/or accumulate. While often being considered ambiguous, Foucault's description of heterotopias, or 'heterotopology', entails six principles, expounded in the following paragraphs.

[I] In the first principle, Foucault states that heterotopias are cultural universals. Although their diversity in form and function is notable, heterotopias can be grouped in two main categories: (a) heterotopias of crisis, such as the boarding schools; (b) heterotopias of deviation, like the psychiatric hospitals or prisons.

[II] The second principle is that the way an existing heterotopia functions can be altered by a society, as its history unfolds. Illustrative for this principle is the heterotopia of the cemetery and the way its function altered through history.

[III] Of particular relevance for this article is the third principle, in which he asserts the thesis that heterotopias can juxtapose within a single place several spaces, emplacements "that are in themselves incompatible" (Foucault, 2008, p. 19). Prime examples for this principle are theatres, cinemas and more importantly, gardens. The latter are described as containing 'deep' and 'superimposed' meanings. For instance, the Persian traditional garden contained within itself representations of all the four parts of the world. In a sense, its sacred character was derived from the fact that the garden juxtaposed in one place multiple spaces. Furthermore, its centre, which consisted of a fountain or a water basin was "still more sacred than the others", because it represented the navel of the world (Foucault, 2008, p. 19). However, it should be emphasized the fact that the gardens don't juxtapose spaces or times per se, but their meaning. This is eloquently highlighted by Foucault when he comments the origins of the carpets, as reproductions of gardens. A similar analogy could be drawn between the nature from the real world and the representations of nature in various virtual worlds, a topic that was approached previously (Burlacu, 2017).

[IV] In the fourth principle Foucault asserts that heterotopias are frequently correlated to 'slices of time', which he calls 'heterochronisms' (Foucault, 2008, p. 20). He claims that a function of heterotopia is fully manifested only when those that find themselves within it are separated from their representation of time. Two categories of heterotopias are derived from this principle: (a) 'heterotopias of time that accumulates indefinitely', such as the cemeteries and museums; (b) heterotopias of transience or festivity, like the carnival.

[V] The fifth principle pertains to a general characteristic of any heterotopia. More specifically, one of the paradoxes of heterotopias is the fact that they all have a system of opening and closing that both isolates them and make them penetrable. Either one can enter in a heterotopia only with a special permission or, conversely, she or he can have the illusion of free entrance, while being unaware of "curious exclusions" (Foucault, 2008, p. 21).

[VI] Finally, heterotopias have always a function in relation to the rest of space. The potential functions of heterotopias are placed by Foucault on a continuum between two 'extremes'. At one pole there is the function of creating 'a space of illusion' that exposes, by contrast, the rest of the normal and/or 'real' space as being even more 'illusory'. For example, 
brothels are such 'heterotopias of illusion'. Oppositely, heterotopias can have the function of creating meticulously ordered spaces, which contrasts the disorder of all the rest of the 'real' space. The Jesuit colonies from South America are such 'heterotopias of compensation' (Foucault, 2008, pp. 21-22). When discussing this principle, there are two things that should be taken into consideration. Firstly, each pole is envisioned by Foucault in a 'double' opposition, both between themselves and also between themselves and the rest of the 'real' space. Secondly, and this is of particular relevance in the case of virtual worlds, the two 'extreme poles' may not be opposite at all. For instance, one of the defining characteristics of multiple distinct places from Diablo III's world of Sanctuary is the fact that they are both illusory and they are meticulously arranged. As a matter of fact, this is an important feature of most virtual heterotopias.

After reviewing Foucault's six principles, one should be careful not to find heterotopic features everywhere. Accordingly, it can be underlined once again the thesis that not every place is a heterotopia (Dehaene and De Cauter, 2008, p. 6). Without accepting this 'axiom', the heterotopia becomes conceptually inconsistent and impossible to use, from an epistemological point of view. Moreover, Foucault's 'heterotopology' contains several polarities that can be used in order to understand the contemporary urban planning, and the design of virtual worlds. The former was addressed in quite a few academic works in the last three decades. In the case of the latter, the books and articles dedicated to the heterotopias that exist in virtual space are far rarer.

\section{Material and methods: Towards a 'heterotopology' of virtual worlds}

It is difficult to use Foucault's principles as a starting point for theorizing 'virtual heterotopias', because it is hard to define them empirically. One can easily compare a virtual world with a landscape simulation. From the earliest 2D arenas from the 1970's and 1980's, followed by the 2D maps from the 1990's, via the isometric 2D of Ultima Online to Everquest's first-person 3D perspective, the evolution was always towards more flexible, more complex and bigger landscapes. In terms of gameplay, not many things have actually changed, as Espen Aarseth states "while the semiotic layer afforded by the graphics and the physics engines keeps improving, it does not seem to have a profound effect on the gameplay" (2008, p. 113). In virtual worlds like Sanctuary from Diablo III or Azeroth from World of Warcraft, meaning is created in a plethora of landscapes and cultural references. Blizzard has succeeded in making worlds that remain fundamentally hollow. In their composition, the emphasis is on the way the various quests are completed and not on what they mean. Indeed, the various places from the two virtual worlds offer little flexibility for the gamer in terms of creating meaning. However, the same thing cannot be said about other virtual worlds, like Second Life.

In order to discern whether or not Foucault's 'heterotopology' can be used to describe these two virtual worlds, the method of participant observation was used. It required an extensive immersion which raised several challenges. One of the most important was a deceptive form of addiction that was very hard to get rid of. Gradually, it became apparent that they could be considered both heterotopias in themselves and juxtaposed collections of heterotopias. Both heterotopias and virtual worlds are paradoxical because they are unreal and illusory, and yet they 'exist' inasmuch as they are constructed. The accessibility of the 'virtual heterotopias' entails a form of 'hyper-illusion' in which the digital counterparts of real elements from the physical world seem more 'real' and 'compelling' than the originals. Similar to Foucault's analogy of the mirror (2008, p.17), from the gamer's standpoint, one can consider that 'virtual heterotopias' are created from the 'Other' part/space of the monitor, reflecting its juxtaposed meanings towards reality. However, this raises one problem: there is always the 'risk' that the gamer may be erased, because at some point she/he is no longer able to authenticate herself/himself upon "the 
Other". Even so, as 'virtual heterotopias' exist, it is important to establish how can be used the Foucault's principles for describing them.

First principle: while heterotopias are cultural universals, their virtual counterparts have proliferated globally, as a result of the rapid Internet expansion from the last two decades. While they are not accessible everywhere, games like World of Warcraft number millions of players. In the research used for this article, 36 guilds from two 'Realms' (i.e. servers) were documented. However, this is only a fraction of the total number of guilds.

Second principle: similar to Foucault's concept, the 'virtual heterotopias' from World of Warcraft and Diablo III have been changed with the introduction of expansion packs. For example, in the case of the first game mentioned, there have been seven expansion packs up until August 2018. They have altered the world of Azeroth considerably. For example, the third expansion, entitled World of Warcraft: Cataclysm (2010) introduced the radical redesign of the continents of Eastern Kingdoms and Kalimdor. In Diablo III, the expansion pack called Reaper of Souls (2014) introduced a new City and multiple dungeons that functioned, by themselves, as heterotopias.

Third principle: a virtual heterotopia juxtaposes in a place several meanings, which represent multiple spaces and times. Azeroth includes thematic zones connected by teleports, portals, roads, ships, mounts and even rail-based transportation. While playing with a Night Elf avatar, their limits were credible. It is necessary to see those zones from above in order to notice the discrepancies between them. For example, in southern Kalimdor, the Un'goro Crater is a lush zone surrounded by three desert zones and a marsh to the north. In the Crater, any player can easily find a bizarre mixture of animals and artefacts. As a matter of fact, the strange juxtaposition of deserts, marshes, jungles and glaciers and the small distances between the antagonistic ethnic groups' settlements are unrealistic, but functional. In Diablo III's world of Sanctuary, the gardens are hyperbolized in numerous areas, in order to condense space and to accelerate time.

Fourth principle: gamers construct the time they spend playing in a manner analogous to the one described by Johannes Fabian, when he refers to the 'denial of coevalness' (1983). Virtual worlds like the ones mentioned above accumulate the gamers' time in a timeless place. Puzzlingly, some of them include zones with associated quests that must be completed in a limited amount of time. In Sanctuary, there are multileveled juxtapositions of several apparently incompatible places, called Nephalem Rifts and Greater Rifts. While they are ephemeral, their results are meticulously registered and stored via an achievement system, in order to determine the player to spend more time in-game.

Fifth principle: accessing some levels from a virtual world is deceptively simple. One gains the impression that she/he is privy to the workings of the game, but is actually excluded from its engine. Open 'sandbox' zones like Velen from Witcher 3 are apparently continuously accessible, but are actually restricted by the number and level of the adversaries, as well as by the quests given. This is actually a constant in open world games: the quests offer the illusion of accessibility, while greatly reducing the openness of the game. In Azeroth, the ridiculousness of the multiple juxtapositions is alleviated only by the artificial boundaries and by the level-based access restrictions: the areas from Teldrassil can be considered an ensemble of absurd places from a functional standpoint. Their accessibility involves a form of 'hyper-illusion' for the beginner Night Elf players.

Sixth principle: all the levels from a virtual world like Sanctuary, all the areas from Azeroth, all the regions from Assassin's Creed: Origins are spaces of illusion. The multiple relations between characters, avatars, and the game mechanics render various representations of reality into a multi-faceted place, which is an elaborated illusion. However, in order to be immersive, these virtual heterotopias include references to real challenges, like the equilibrium 
between nature and technology, tolerance for the various hypostases of the 'Other', resource production and distribution etc.

\section{Conclusions}

Adapting Foucault's 'heterotopology' to virtual worlds is an endeavour that should be undertaken while accepting the fact that not all the virtual places are heterotopias. In Azeroth and Sanctuary space is describable only in relation to time and vice-versa: there are no gaps. This gives the illusion of continuity, by avoiding the inevitable gaps from the worlds imagined by various authors of fiction. Without the repetitive activities from other fictional worlds, Azeroth and Sanctuary may appear to be more 'authentic'.

In conclusion, Foucault's principles can be used for describing virtual worlds. Thus, by immersing in these two worlds, it is possible to ascertain that they are both heterotopias in themselves and collections of smaller heterotopias. Furthermore, they tend to have a nucleus that functions like an 'engine' for the continuation of their existence. The uninterrupted change of meaning caused by "virtual heterotopias" leads to the emergence of new implications and the development of new virtual places. That is why such heterotopias are far greater reserves of imagination than their counterparts imagined by Foucault. In adapting the original 'heterotopology' for describing 'virtual heterotopias', a particular importance should be given to Foucault's third and sixth principles. Also, it is important to emphasize the fact that from a semiotic standpoint, 'virtual heterotopias' tend to continuously transform their meaning on multiple levels. This feature may open new ways of understanding space and place in virtual contexts, from an anthropological point of view.

\section{Bibliography}

1. Aarseth, E., 2008. A hollow world: World of Warcraft as spatial practice. In: H. G. Corneliussen and J. W. Walker (Eds.). Digital Culture, Play, and Identity: A World of Warcraft Reader. Cambridge and London: The MIT Press. pp. 111-122

2. Boyer, C.M., 2008. The many mirrors of Foucault and their architectural reflections. In: M. Dehaene and L. De Cauter (Eds.). Heterotopia and the City: Public Space in a Postcivil Society. London and New York: Routledge. pp. 53-73.

3. Burlacu, M., 2014. Digital anthropology: Theoretical perspectives regarding electronic tribes. Bulletin of the Transilvania University of Braşov. [e-journal] 7(56), pp. 241-248. Available

at: http://webbut.unitbv.ro/BU2014/Series\%20VII/BULETIN\%20VII\%20PDF/26_BURLACU \%201-2014.pdf [Accessed 5 July 2019].

4. Burlacu, M., 2015. The 'Zone' as heterotopia in Andrei Tarkovsky's Stalker. Bulletin of the Transilvania University of Braşov. [e-journal] 8(57), pp. 69-76. Available at: http://webbut.unitbv.ro/BU2015/Series\%20VII/BULETIN\%20I/10 Burlacu.pdf [Accessed 5 July 2019].

5. Burlacu, M., 2017. The 'virtual heterotopias': Reimagining nature-culture relations. Český Lid. [e-journal] 104(2), pp. 183-197. http://dx.doi.org/10.21104/CL.2017.2.01

6. Dehaene, M. and De Cauter, L., 2008. Introduction: Heterotopia in a postcivil society. In: M. Dehaene and L. De Cauter (Eds.). Heterotopia and the City: Public Space in a Postcivil Society. London and New York: Routledge. pp. 2-9.

7. Fabian, J., 1983. Time and the Other: How Anthropology Makes Its Object. New York: Columbia University Press. 
8. Faubion, J. D., 2008. Heterotopia: An ecology. In: M. Dehaene and L. De Cauter (Eds.). Heterotopia and the City: Public Space in a Postcivil Society. London and New York: Routledge. pp. 31-39.

9. Foucault, M., 2002. The Order of Things: An Archaeology of the Human Sciences. London and New York: Routledge.

10. Foucault, M., 2008. Of other spaces. M. Dehaene and L. De Cauter (Eds.). Heterotopia and the City: Public Space in a Postcivil Society. London and New York: Routledge. pp. 13-22.

11. Hetherington, K., 1997. The Badlands of Modernity. London and New York: Routledge.

12. Palfrey, J. and Gasser, U., 2008. Understanding the First Generation of Digital Natives. New York: Basic Books. 